\title{
Deterioro del tejido social, violencia y criminalidad
}

\begin{abstract}
Al cierre del año 2000 , los balances y las valoraciones globales de lo sucedido en El Salvador se vuelven inexorables. Se ha tratado de un año difícil para la sociedad en su conjunto, pero especialmente para los sectores populares que han visto como, desde las esferas estatales, se han impulsado una serie de medidas socioeconómicas cuyo propósito no ha sido ni por cerca mejorar sus condiciones de vida. Las últimas medidas económicas emprendidas por el gobiemo de Francisco Flores - concretamente, la Ley de Integración Monetaria, la firma de un Tratado de Libre Comercio y la creación de un Fondo Vial' - así lo corroboran. Ya desde antes, con las reformas encaminadas a la privatización y la modernización del Estado, se había apuntado en la misma dirección: hacer aún más inciertas las posibilidades de sobrevivencia de los sectores mayoritarios del país. La dolarización en ciernes no parece prometer nada mejor para los salvadoreños más desposeídos; más bien, al contrario, es probable que se traduzca en alzas de precios de los bienes de consumo básico, con lo cual se agravarán las condiciones de vida de los sectores populares ${ }^{2}$.
\end{abstract}

Durante el año 2000 se ha vuelto a poner de manifiesto, como en años anteriores, la pasividad de la mayor parte de la población ante las decisiones que emanan de los círculos de poder político. Es cierto que ha habido brotes de descontento social, pero éstos se han focalizado en grupos muy redu- cidos y con intereses muy particulares - como es el caso de los desmovilizados de la Fuerza Armada-, sin lograr articularse con intereses y demandas de alcance más general. Es decir, las manifestaciones de descontento social de grupos como los ex patrulleros, con todo lo justificadas que puedan ser, difícilmente pueden ser vistas como expresión de intereses globales de la sociedad. Son manifestación del malestar de un sector bien definido de la sociedad que se siente excluido de los beneficios de los acuerdos de paz. Es de presumir que una vez que sean satisfechas sus peticiones, los desmovilizados cesarán en sus manifestaciones de violencia callejera. La lucha de los ex patrulleros no busca ni trascender unas determinadas demandas puntuales — básicamente de tipo económico- ni articularse con demandas de otros sectores sociales más amplios.

En otro orden, se han generado experiencias novedosas de participación social en zonas rurales del país - concretamente, en el nororiente del departamento de Chalatenango o al norte del departamento de Morazán-, pero esas experiencias no son generalizadas ni involucran siquiera a la mayoría de habitantes de los municipios en que se realizan. Se trata de experiencias de participación social que no sólo se llevan adelante en antiguas zonas de guerra, sino que las mismas involucran a poblaciones que durante el pasado conflicto armado

1. Ver "El paquete de medidas económicas del gobierno", El Salvador Proceso 931, 13 de dicicmbre de 2000, pp. 7-8.

2. Ver "Dolarización ipara quién?", Carta a las Iglesias 463-464, 1-31 de diciembre de 2000, pp. 4-5. 
se vincularon directa o indirectamente al FMLN. EI (re)aprendizaje organizativo de estos habitantes rurales está siendo particularmente difícil, no sólo porque la guerra y el exilio dejaron amargos recuerdos, sino porque tienen que romper con patrones de organización que los subordinaban a una estructura político militar. Recuperar su autonomía, forjar nuevos liderazgos, reconstruir sus comunidades, enfrentar el desafío cotidiano de la precariedad y la pobreza: esos son los retos de los pobladores tanto del norte de Morazán como del nororiente de Chalatenango.

Así, pues, desde el punto de vista de la participación y organización de la sociedad civil, el año 2000 no deja logros significativos respecto de años anteriores. Falta mucho que hacer todavía para superar la pasividad y la apatía que caracterizan el comportamiento público de la mayor parte de la población. Ahora hay más posibilidades y oportunidades para avanzar en esa dirección; empero, la tarea requiere dosis ingentes de creatividad y compromiso que, por el momento, brillan por su ausencia. Se trata de aprovechar al máximo los espacios legales, institucionales y locales, abiertos a partir de 1992, para potenciar y encauzar la participación de la sociedad civil, a sabiendas de que sin esa participación lo que se diga de la democracia será siempre insuficiente. Se ha dicho hasta la saciedad, pero siempre vale la pena insistir en ello: la democracia es un régimen político, y como tal exige elecciones periódicas, separación de poderés, libertad de expresión, pluralismo ideológico-político y tolerancia. Pero también es una forma de vida, un modo de relacionarse con los demás, de convivir en paz y tranquilidad. Esta convivencia tranquila y pacífica debe ser obra cotidiana de todos los ciudadanos, debe ser resultado de una firmes convicciones democráticas. Porque, en definitiva, "la democracia es el respeto hacia los demás, correspondido por el respeto que recibe uno mismo de los demás... un sistema realmente democrático no exime al ciudadano de seguir ejerciendo su responsabilidad civil durante los períodos interelectorales. Los ciudadanos no votan cada cuatro años, sino diariamente, aplaudiendo o disintiendo"?.

Más concretamente, la participación social es clave para reconstruir el tejido de la sociedad sal- vadoreña, corroído por el crimen, la prepotencia, la impunidad y los resabios autoritarios presentes en la cultura política nacional. Son abundantes los argumentos sobre el deterioro de la convivencia social en El Salvador de la postguerra. Los lazos de solidaridad se han roto y con ello las posibilidades de una convivencia social segura. Esta es la raíz de la crisis de la seguridad ciudadana que tanto preocupa no sólo a las autoridades, sino también al ciudadano común ${ }^{4}$. Es tan grave la situación de inseguridad, que muchos salvadoreños optan por dejar el país en busca de sociedades donde sus vidas y sus bienes no se vean tan amenazados como aquí.

Múltiples factores hacen insegura la vida en $\mathrm{El}$ Salvador, pero entre los más graves está la amenaza permanente de criminales de toda especie - violadores, secuestradores, asaltabancos, estafadores, robacarros, delincuentes callejeros- Obviamente que de las actividades criminales, los secuestros son los que más incidencia pública han tenido durante el año 2000 , de tal forma que se han convertido en el centro de atención de los medios de comunicación social. Pero, aunque graves y preocupantes, los secuestros no lo son todo. Datos consolidados para 1997 — cuyas tendencias se han mantenido durante los dos años siguientes- arrojan una tasa aproximada de homicidios de 134 por cada 100 mil habitantes, 17 mil delitos contra el patrimonio — robos, hurtos, daños a propiedades-, la mayor parte de ellos acompañados de violencia. Si a ello se suman las actividades de narcotráfico que involucran a redes criminales centroamericanas, los desafíos de la seguridad pública se vuelven todavía más problemáticos ${ }^{5}$.

Por otra parte, en cada nivel social los riesgos ante el crimen son distintos, pero prácticamente nadie en El Salvador está exento de ser agredido por el primero que quiera abusar de él. Cada cual, a su manera y a su estilo, busca aprovecharse de los demás, imponerse sobre ellos, demostrar su fuerza y poder. Los delincuentes llevan esta situación hacia límites extremos; sin embargo, la laceración de los derechos y la dignidad de sus semejantes no es tarea exclusiva de ellos. Aunque cuesta aceptar que el salvadoreño promedio está presto a pisotear la dignidad de su prójimo — su "próximo"-, siempre que vea en ello una oportunidad para obtener algo a cambio,

3. Ramón Folch, "Democracia", en Diccionario de socioecología, Barcelona, Planeta, 1999, p. 95.

4. Ver Editorial "La seguridad en crisis", ECA 619-620, mayo-junio, 2000, pp. 493-510.

5. Ver La cultura de la violencia en El Salvador. Número monográfico. ECA 588, octubre, 1997. 
aunque sólo sea la confirmación de su prestigio social, hay evidencia suficiente como para sostener una afirmación de esa naturaleza.

Se suele creer que los delincuentes forman un mundo aparte, que son seres radicalmente distintos a los demás; es decir, se suele creer que existe una separación tajante entre criminales y no criminales. Pues bien, en El Salvador - al igual que en otras sociedades latinoamericanas - tal separación no es ni tan nítida, ni tan absoluta como se quiere pensar. No sólo abundan las personas "decentes" y de "buena familia" involucradas en actividades criminales de altos vuelos, sino que a la salida del trabajo, en la puerta de la casa o en la escuela cualquiera traspasa los límites de la legalidad con toda naturalidad, por no hablar de quienes los bordean hasta niveles criminales por una disputa de tránsito o por una discusión al calor de un par de copas.

Quizás no sea descabellado proponer la hipótesis de que en cada salvadoreño hay un criminal en potencia que, en la primera oportunidad, violenta la dignidad de los demás. Esta hipótesis puede ser útil, primero, para tomarse con reservas la separación tajante entre delincuentes y no delincuentes -entre "ellos" (los criminales) y "nosotros" (los decentes) - y tratar de entender la complejidad social del crimen.

En segundo lugar, la hipótesis puede ser iluminadora a la hora de abordar el problema de la erradicación del crimen. Si todos tenemos un potencial de criminalidad, todos debemos someternos a un proceso de cambio personal y social. Todos debemos cuidarnos de nosotros mismos, antes que del vecino o del que se cruza en nuestro camino, porque nadie asegura que no seamos nosotros los agresores. Si el círculo de la violencia involucra, en igualdad de condiciones, un "ellos" y un "nosotros", cambia radicalmente la responsabilidad y el compromiso de cada uno con el problema, puesto que ya no se trata de buscar a los culpables "fuera de casa", sino dentro de ella.

Claro está, el argumento tiene sus riesgos. Uno de ellos es que puede tomarse como una invitación a sospechar de todo y de todos. Este riesgo no lo es tanto pues, como están las cosas en el país, efectivamente todos sospechan de todos, del desconocido,

del que se viste con pantalones flojos, del que tiene tatuaje, de quien usa un vehículo con vidrios polarizados. Esto es, se sospecha de todos los demás, menos de uno mismo. Lo que se propone es que, si se sospecha de todos, nosotros mismos debemos ser sometidos a sospecha, ya que, si se mira detenidamente el problema de la violencia, resulta que muchos de los que aparecen involucrados en ella comparten con los pretendidos no criminales no sólo estatus social, sino educación, aspiraciones y costumbres. Muchos de ellos son salvadoreños, hijos de salvadoreños, educados formal o informalmente en este país, con sueños truncados a ambiciones exageradas, al igual que la gran mayoría de sus habitantes.

Dicho de otro modo, sólo si quienes se consideran no violentos o no criminales se ven como parte -aunque sea potencial- de la violencia y el crimen que invade al país, quizás sea posible que la sociedad en su conjunto asuma con seriedad ambos problemas. Ver el crimen y la violencia como algo de lo cual otros son responsables no es ni realista ni recomendable en un país como El Salvador, donde la violencia y el crimen afectan a prácticamente todos los ciudadanos. Pero no los afecta desde fuera, como un agente externo y localizado, sino desde dentro, en su convivencia cotidiana, familiar, social y laboral.

En otras palabras, la violencia y la criminalidad han invadido el tejido social de El Salvador, tanto al nivel horizontal como al nivel transversal. La categoría de violencia social hace referencia, precisamente, a esa permeabilización de la sociedad por obra de la criminalidad en todas sus mani- 
festaciones. Hasta ahora, no aparecen en el horizonte señales que indiquen un cambio de rumbo, sino más bien todo lo contrario. Y lo que es peor, todo indica que el país se encamina hacia un mayor deterioro del tejido social, del que sólo podrá salir a partir de un cambio drástico en los usos y las costumbres de quienes, al amparo de unas instituciones poco sólidas, han hecho de la fuerza, la prepotencia y el abuso una forma de vida ${ }^{6}$.

Un cambio de esta naturaleza forzosamente debe articularse -y ser sostenido- por un cambio institucional que deberá estar regido por las normas y los valores de la democracia. Y es que el problema de la seguridad ciudadana es inseparable del problema de la construcción de un orden democrático, al cual debe responder tanto en sus requisitos particulares como en su globalidad. En efecto, la seguridad ciudadana en una democracia no es una seguridad conseguida a cualquier precio o impartida exclusivamente desde arriba — desde el poder estatal-, sino algo en lo que, al menos en teoría, deben involucrarse los diversos sectores sociales.

Una seguridad ciudadana sin participación social fácilmente se puede decantar hacia estilos de seguridad autoritarios, en los cuales se termina por socavar aquello que se dice defender. La doctrina de la seguridad nacional asumida por los gobiemos militares en El Salvador, desde finales de los años sesenta, debe convertirse en un referente contra esas visiones de la seguridad que ven en el aparato estatal a su garante exclusivo. La principal limitación de estas visiones es que desembocan en una concepción "centralista" de la seguridad, es decir, en una concepción según la cual es desde el gobierno central de donde deben emanar las líneas maestras para la consecución de la seguridad ciudadana?.

Si la criminalidad y la violencia han permeado al conjunto de la sociedad, la tarea de superar ambas situaciones se vuelve particularmente difícil. Indudablemente, una reforma cultural aparece en el horizonte como una condición sine qua non para tal propósito. La violencia y la criminalidad se alimentan de valores, creencias, actitudes y prácticas —en suma, un marco cultural-simbólico- no sólo arraigadas en quienes abiertamente delinquen, sino en la mayoría de los ciudadanos. Es decir, en El Salvador persisten esquemas culturales en los que se valora positivamente a la fuerza, la agresividad, la prepotencia y la sumisión a la autoridad como estilos ideales de comportamiento. Es decir, hay esquemas culturales autoritarios heredados del pasado que favorecen el abuso y la violencia sobre los más débiles ${ }^{8}$. Y esto de un modo generalizado en el conjunto de la sociedad.

Un cambio en ese marco cultural-simbólico, una transformación cultural, se vuele ineludible si se quiere transitar de un clima de violencia social a una situación de convivencia social pacífica. Ese nuevo marco cultural simbólico no puede ser otro que el que se asiente en la solidaridad, el respeto a la dignidad del otro, la fraternidad, la tolerancia y la hospitalidad.

Asimismo, además de un marco cultural-simbólico distinto, el tránsito de un clima de violencia social a un clima de tranquilidad social requiere una reforma institucional de largo aliento, la cual esté encaminada a combatir la prepotencia, la impunidad y corrupción en todos los niveles de las esferas gubernamentales. Sin una reforma de esta naturaleza, las instituciones estatales van a ser incapaces de recuperar la legitimidad perdida a lo largo de todos estos años. A su vez, van a ser incapaces de dar su contribución a la recomposición del tejido social salvadoreño.

El año 2000 deja retos ineludibles en el plano cultural y en el plano institucional. Ambos retos sólo podrán ser enfrentados en el futuro con una sociedad civil organizada y participativa y con unos ciudadanos conscientes de sus derechos y responsabilidades. Los actores políticos, las universidades, los organismos no gubernamentales, las autoridades de gobierno, los sindicatos, los empresarios... Todos los sectores sociales tienen una tarea que realizar en orden a reconstituir los lazos de solidaridad social en el país. Un fracaso en esta dirección condenará al país -y a todos sus habitantes- a la inseguridad, el miedo y la incertidumbre, caldo de cultivo para la reproducción de la violencia y la impunidad.

\section{Luis Armando González Director del Centro de Información, Documentación y Apoyo a la Investigación (CIDAI) de la UCA}

6. Ver "El fenómeno de la violencia en El Salvador", El Salvador Proceso 929, 29 de novicmbre de 2000, pp. 2-3.

7. Ver "El gobierno ante la seguridad ciudadana", El Salvador Proceso 931, 13 de diciembre de 2000, pp. 2-3.

8. Ver Instituto Universitario de Opinión Pública (IUDOP), Encuesta sobre valores, San Salvador, IUDOP, 1999. 